\title{
Use of a Simple Fabrication Process to Produce a Biosensor: The 3-Hydroxybutyrate Dehydrogenase Case
}

\author{
I. Ribau and E. Fortunato \\ CENIMAT/I3N, Departamento de Ciências dos Materiais, Faculdade de Ciências e Tecnologia, FCT, Universidade Nova de Lisboa, \\ Campus de Caparica, Caparica 2829-516, Portugal
}

\begin{abstract}
This study was aimed to construct a biodegradable but reliable 3- $\beta$-hydroxybutyrate biosensor. In this context a versatile paper based biosensor, quickly, easily and cheaply fabricated is reported. The procedure of fabrication is based on the assumption that the introduction of the enzyme in the carbon ink will allow enzyme stabilization and facilitate the study of the catalysis of enzymes and the detection of substrates. To prove this concept we use the enzyme 3-hydroxybutyrate dehydrogenase, in aqueous solution. This enzyme was chosen because it catalyzes the 3 - $\beta$-hydroxybutyrate, which results from ketoacidosis. The quantification this substance in the diabetics' blood is very important as it can increase the reliability of the diagnosis of glycaemia. To prove the multi-use of this biosensor we not only study the redox process in steady state and during the catalytic process, but also detected and quantify the 3 - $\beta$-hydroxybutyrate. Our results showed that it was possible to study the redox process that occurred during the catalysis and to confirm the amino acid residues that participate in it. It was also observed that glucose and ascorbic acid can interfere in the detection and quantification of the 3- $\beta$-hydroxybutyrate, what should be in mind when the quantification of the 3- $\beta$-hydroxybutyrate is made in blood samples.
\end{abstract}

Key words: Diabetics, paper biosensor, screen-printing, 3- $\beta$-hydroxybutyrate dehydrogenase.

\section{Introduction}

The diabetic population increased and the perception of the consequence that it can cause not only to the individual (diseases, death, and inability to work) but also to the society (health care, economic impact on health system) lead to the necessity of its control [1-3]. The production of biosensors that can be cheap, easily made, reproducible and reliable are a goal that will allow the universalization of sensor coupled POC (point-of-care) diagnostic devices.

The use of glucose sensors coupled POC diagnostic devices, also known as glucometers, is one of the most used methods nowadays to measure the blood glucose concentration. Although it is simple, quick and an easy way to measure the glucose concentration, and monitor glucose levels, it is expensive since usually diabetics should know this information daily, and also is not free

Corresponding author: Isabel Ribau, Ph.D., researcher, research fields: biosensors and bioelectrochemistry. of risks [3-10]. In diabetic patients, the ketoacidosis analysis is essential to prevent wrong diagnostics in diabetics' type 1 . In healthy individuals, normal amounts of 3- $\beta$-hydroxybutyrate are below $1 \mathrm{mM}$, in individuals with hyperketonaemia this value can range from $1 \mathrm{mM}$ to $3 \mathrm{mM}$ [11-12].

The rapid determination of 3- $\beta$-hydroxybutyrate in blood is crucial to a quick and correct diagnosis, but only few 3- $\beta$-hydroxybutyrate biosensors have been reported and some of them are screen-printing electrodes [11, 13, 14]. In some of these sensors, lost in enzyme activity is reported, and attributed to mediator inhibition. They also report interferences with other electro active species in solution.

Some of these amperometric biosensors are based on redox mediators' reactions $[15,16]$. The mediators used were 1,10-phenanthroline quinine and potassium ferricyanide. However, none of these systems detects 3 - $\beta$-hydroxybutyrate directly, increasing the system complexity and cost. 
There are many advantages of development biosensors that can directly sense the presence of 3 - $\beta$-hydroxybutyrate, using a simple enzymatic system 3-Hydroxybutyrate Dehydrogenase (HBH). In this context we developed a simple biosensor that, without modification of the surface working electrode, makes possible the detection of 3- $\beta$-hydroxybutyrate.

$\mathrm{HBH}$ is an oxidoreductase that presents a tetrameric structure. In each subunit of the tetrameric enzyme, the substrate (D-3-hydroxybutyrate) is trapped on the nicotinamide plane of the bound $\mathrm{NAD}^{+}$, and it has bounds to the amino acid chain [17] (Fig. 1).

The methyl group of the $\mathrm{NAD}^{+}$is accommodated in the nearby hydrophobic pocket, which makes possible a hydrogen bond from the $\mathrm{OH}$ group of the substrate to the hydroxyl group of Tyr155 at the active center. A comparison of the protein structure with and without ligands indicates that the Gln196 residue participates in the formation of additional hydrogen bonds. It is likely

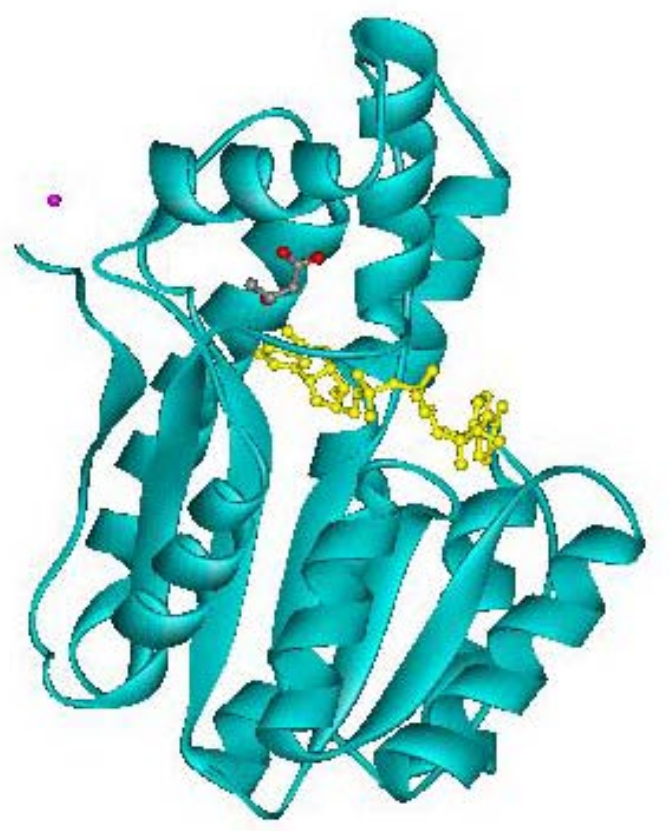

Fig. 1 PDB crystal structure of a tetramer unit of $\beta$-3-hydroxybutyrate dehydrogenase from Alcaligenes faecalis, complexed with $\mathrm{NAD}^{+}$(in the middle in yellow) an $\mathrm{Na}$ atom in the top (purple) near the amino acid chain (light blue) and a substrate $\beta$-3-hydroxybutyrate (gray and red) (PDB code: 5B4T) [16]. Figure prepared with Viewerlite program. that this situation can facilitate $\mathrm{H}$-atom movements as the trigger of the catalytic reaction [17].

The redox system $\mathrm{NADH} / \mathrm{NAD}^{+}$is very important in nature since it is a cofactor of a large number of enzymes, but also because it is important in biofuel cells and bioreactors [18-20]. However, it is also a challenge to develop biosensors, once there is the possibility of $\mathrm{NAD}^{+}$freely lives the enzyme, becoming the enzyme in an inactive conformation, but also the formation of inactive products $\left(\mathrm{NAD}_{2}\right.$ dimer). Another problem is that the oxidation of NADH is usually irreversible, it occurs at high potential, $\mathrm{NAD}^{+}$act as an inhibitor of the direct electrode process or even provokes electrode surface poisoning [21-24]. To overcome these difficulties, efforts have been made using different strategies as surface modification, use of mediators [13, 16, 25-27] or use new materials (carbon nanofibers, carbon nanotubes, graphene and composites) as immobilization matrix for biomolecules [18, 19, 22, 28-34]. These paper devices are screen-printing electrodes that have an important role in the biosensing development, once they have numerous applications in biochemical fields [35-38]. The versatility of these devices, which can sense diverse substances (from metals to enzymes, pesticides, antigens, biomolecules) and are easily made, give a fundamental place in the electrochemical research nowadays.

We used the system $\mathrm{HBH} / \mathrm{NAD}^{+}$as the key base to develop a new biosensor $[39,40]$. The electron transfer occurs between the redox active enzyme center and the electrode surface and allows the use of the redox couple $\mathrm{NADH} / \mathrm{NAD}^{+}$as a reliable source of information related to the detection of 3 - $\beta$-hydroxybutyrate with a $\beta$-3-hydroxybutyrate dehydrogenase $/ \mathrm{NAD}^{+}$biosensors.

\section{Experimental}

\subsection{Materials}

All reagents used were of analytical grade. 3-hydroxybutyrate dehydrogenase (HBH) from 
Rhodobacter sphaeroids (aqueous solution (2 mL), 10 $\mathrm{mg}$ ), was used with no further purification, 3- $\beta$-hydroxybutyrate, $\quad \beta$-nicotinamide adenine dinucleotide, reduced disodium salt hydrate (NADH), potassium chloride and potassium ferrocyanide were acquired from Sigma-Aldrich. All buffers used in this work were commercial and purchased from ROTH (Germany). The electrolyte was a buffer solution with potassium chloride $(0.1 \mathrm{M})$. All solutions were prepared with electrolyte.

\subsection{Fabrication of the Biosensor}

The carbon ink and $\mathrm{Ag} / \mathrm{AgCl}$ ink were purchased from Conductive compounds. The ink base of the working electrode was the carbon ink in which was added enzyme.

A Xerox Color Qube 8570 printer from Xerox was used to print the hydrophobic region of the devices. The paper used was Whatman n. ${ }^{0} 1$ chromatographic paper, and the wax was obtained from Xerox. After the wax printing, the wax was heat treated during $10 \mathrm{~s}$ in a hot plate $\left(150^{\circ} \mathrm{C}\right)$. After that, the paper, cooled at room temperature and it was ready to perform the screen-printing technique. The configuration system designed was a three electrode system with an $\mathrm{Ag} / \mathrm{AgCl}$ reference electrode, a carbon counter electrode and a working electrode based in carbon ink. The conductive circuit was screen-printed with silver ink, which was deposited above the hydrophobic matrix (wax). Then the mesh was removed and the device was allowed to heat at hot plate $\left(60^{\circ} \mathrm{C}\right)$ during 8 minutes. Once the construction of the conductive circuit was concluded, the counter electrode was printed and dried the same way as described before. The other two electrodes had the same screen-printing treatment.

\subsection{Working Electrode Preparation}

The enzyme, in aqueous solution, and cofactor, in the solid state, were mixed with the carbon ink. This mixture was used to do the working electrode.

\subsection{Electrochemical Detection}

During the electrochemical measurements, a drop of the interest solutions $(2 \mu \mathrm{L})$ is spotted in the hydrophobic channel between the wax-limited zones and dispersed through the paper matrix in a few seconds, being in contact with the three electrodes. The electrochemical behavior of enzyme was experimentally characterized through cyclic voltammetry.

All electrochemical acquisitions and measurements were performed in a Gamry ESA419 data acquisition system, using PHE 200 physical electrochemical and PV 220 physical electrochemical software coupled with a Gamry instruments (reference 600) potentiostat/galvanostat (ZRA) and the data analysis were processed by Gamry software package. All the experimental procedure was performed in normal atmosphere in the presence of oxygen.

\section{Results and Discussion}

The major goal of this research was to fabricate a 3- $\beta$-hydroxybutyrate biosensor that did not need a mediator, as in the previous biosensors reported, which not only would decrease the price of the apparatus but also nullifies its influence in the biosensor detection-mediator inhibition. The simplification and the reduction of time-consuming in the biosensor manufacture, in comparison to previous ones, were another aim of this research (see 2.2 Fabrication of the biosensor). To ensure the enzyme activity-one of the problems reported in earlier research - the strategy was to introduce the enzyme as it was purchased and its cofactor NADH, in the working electrode mixture. The results obtained are described below.

\subsection{Electrochemistry of HBH Using a Screen-Printing Electrode}

With the aim of developing a 3- $\beta$-hydroxybutyrate (HB) biosensor, a metabolite produced by the human body, we developed a screen printing biosensor that can sense its presence. To achieve this objective, we fabricated a working electrode using a mixture of 
NADH (35 mg) and HBH (0.25 mg) in carbon ink (814 mg). The addition of the cofactor NADH was to ensure the enzyme activity.

The cyclic voltammograms were recorded at room temperature $\left(22{ }^{\circ} \mathrm{C}\right)$, at sweep rate between $20-100$ $\mathrm{mVs}^{-1}$. The direct electron transfer between the redox active center and the electrode surface occurred at low potentials (Fig. 2).

Two well-defined anodic and cathodic peak currents appeared in the voltamogramas. To ensure the repeatability of the results, more six experiments were conducted in the same conditions using six different screen printing electrodes.

Using the data of the seven experiments, using seven different biosensors, it was possible to obtain the following results: a well-defined cathodic peak appears at $\mathrm{E}_{\mathrm{p}}{ }^{\mathrm{a}}=81 \pm 6 \mathrm{mV}$ and anodic peaks, were observed at $E_{\mathrm{p}}{ }^{\mathrm{c}}=-134 \pm 27 \mathrm{mV}$. A peak-to-peak separation, $\Delta E \mathrm{p}$, with a value of $(232 \pm 14) \mathrm{mV}$ vs $\mathrm{Ag} / \mathrm{AgCl}(\mathrm{n}=7)$ was obtained and a formal potential of $\mathrm{E}^{0,}=(-26.5 \pm 10)$ $\mathrm{mV}$ vs. $\mathrm{Ag} / \mathrm{AgCl}(\mathrm{n}=7)$ was calculated. A ratio of anodic to cathodic peaks current, $\left|i_{\mathrm{p}}{ }^{\mathrm{a}} / i_{\mathrm{p}}{ }_{\mathrm{c}}{ }^{\mathrm{A}}\right|$ was also estimated near the unit. Although $E_{\mathrm{p}}$ and $\mathrm{i}_{\mathrm{p}} / \mathrm{v}^{1 / 2}$ are independent of the scan rate, $\left|i_{\mathrm{p}}{ }^{\mathrm{a}} / i_{\mathrm{p}}{ }^{\mathrm{C}}\right|$ is near the unit, peak-to-peak variation, $\Delta E \mathrm{p}$, is far from the theoretical value $(59 / \mathrm{n}(\mathrm{mV}), \mathrm{n}=$ electron number). The parameters obtained in these experiences reflect a quasi-reversible redox process, controlled by diffusion [40-42].

\subsection{Catalysis of 3- $\beta$-Hydroxybutyrate by $\mathrm{HBH}$ Using a} Screen-Printing Electrode

Cyclic voltammetry was used to analyze the behavior of $\mathrm{HBH}$ in the presence of increasing concentrations of $\mathrm{HB}$. The direct catalysis of 3-hydroxybutyrate dehydrogenase ( $\mathrm{HBH})$ activated (HBH with cofactor- $\mathrm{NADH}$ ) in $\mathrm{pH} 7$ was observed. The voltammetric data obtained in these conditions at the screen printing electrodes were assigned to the redox process involving the $\mathrm{NADH}$ and the $\mathrm{HBH}$ catalytic center. An increase in the cathodic peak current was observed during 3- $\beta$-hydroxybutyrate additions. The calibration curve in the presence of different concentrations of HB is shown in Fig. 3.

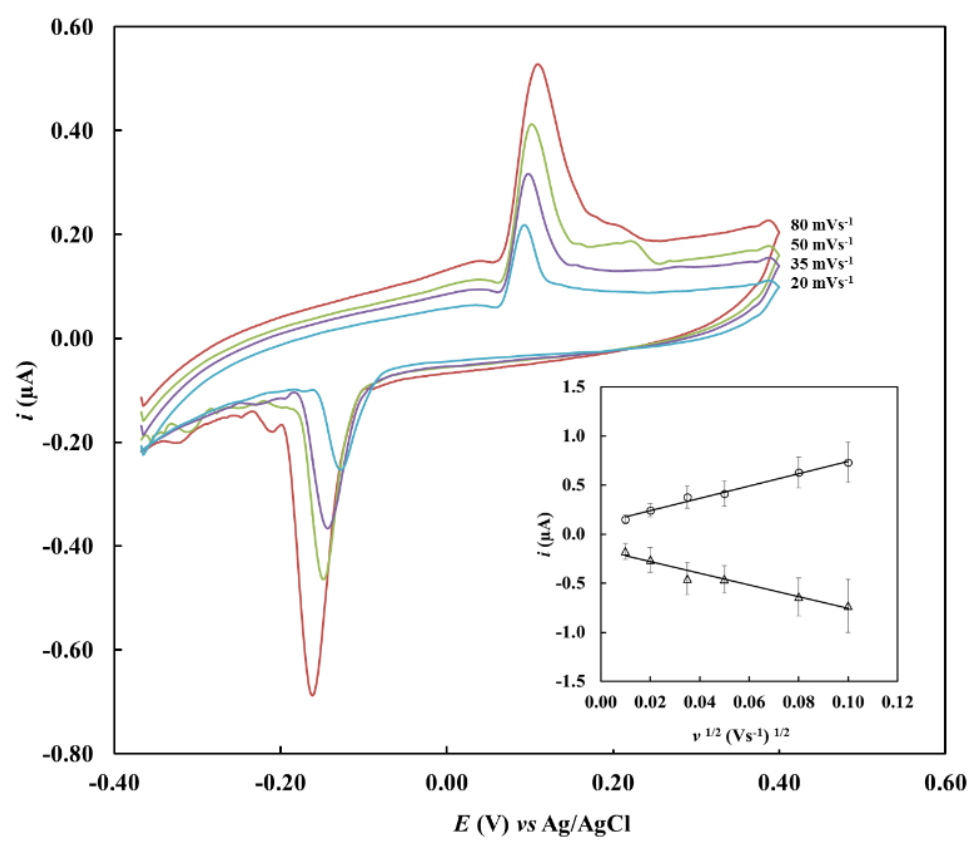

Fig. 2 Cyclic voltammograms at a screen at a screen printing electrode with a three electrode system configuration with an $\mathrm{Ag} / \mathrm{AgCl}$ reference electrode, a carbon counter electrode and a working electrode with NADH (35 mg) and HBH (0.25 mg) in carbon ink (814 mg) in $2 \mu \mathrm{L}$ of PBS (7.0) with $\mathrm{KCl}(0.1 \mathrm{M})$. Insertion: Variation of the anodic and cathodic peak current with the square root of the sweep rate. (:) $\left.i_{\mathrm{p}}{ }^{\mathrm{a}}=2.627 \mathrm{v}^{1 / 2}+0.118 \mu \mathrm{A}, \mathrm{R}=0.99, \mathrm{n}=7 ;(\Delta) i_{\mathrm{p}}{ }^{\mathrm{c}}=-2.592 \mathrm{v}^{1 / 2}+0.076 \mu \mathrm{A}, \mathrm{R}=0.99, \mathrm{n}=7\right)$. 


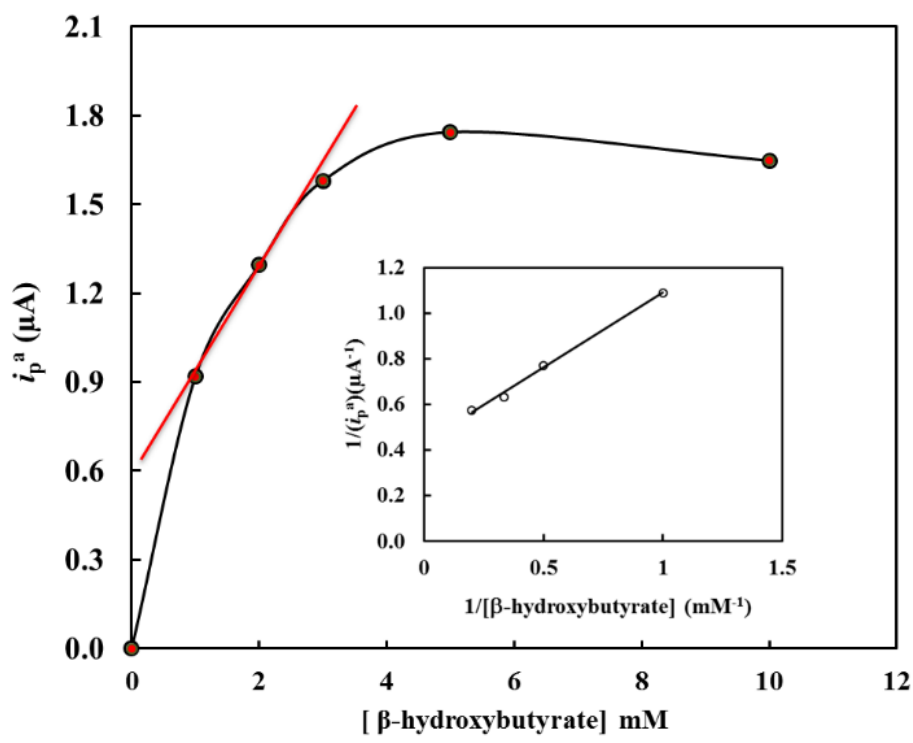

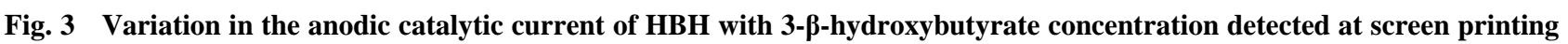
electrode with a three electrode system configuration with an $\mathrm{Ag} / \mathrm{AgCl}$ reference electrode, a carbon counter electrode and a working electrode with NADH and HBH in carbon ink. The voltammograms were recorded in $2 \mu \mathrm{L}$ of PBS (7.0) with KCl (0.1 M) with different 3- $\beta$-hydroxybutyrate concentration. Insertion: Michaelis-Menten Lineweaver-Burk linearization: $1 / \mathbf{i}_{\mathbf{p}}{ }^{a}=$ $0.6561 /\left[3-\beta\right.$-hydroxybutyrate] $+0.4332, \mathrm{R}^{2}=0.9965, \mathrm{~K}_{\mathrm{m}}=1.54 \mathrm{mM}, \mathrm{I}_{\mathrm{cat}}{ }^{\mathrm{max}}=2.3 \mathrm{mM}$. The best curve fit to Michaelis-Menten kinetics (-); Linear variation of anodic catalytic current between 1 and $3 \mathrm{mM}$ of 3 - $\beta$-hydroxybutyrate was $i_{\mathrm{p}}{ }^{\mathrm{a}}=0.330$ [3- $\beta$-hydroxybutyrate] $+0.603, \mathrm{R}^{2}=0.9936, \mathrm{n}=3$ (three measurements) for each point $(-)$.

The addition of 3 - $\beta$-hydroxybutyrate produced a slight change in the electrochemistry parameters to: $\Delta E \mathrm{p}=(239 \pm 15) \mathrm{mV}$ vs. Ag/AgCl $(\mathrm{n}=13)$, and the estimated $\mathrm{E}^{0,}=(-22.0 \pm 9) \mathrm{mV}$ vs. $\mathrm{Ag} / \mathrm{AgCl}(\mathrm{n}=13)$. The formal potential, $\mathrm{E}^{0}$, is near the value obtained in buffer solution signifying that the redox groups responsible for the catalytic process and for oxidation and reduction in non-turnover conditions are the same.

The reaction that occurs in the catalytic center is the following one:

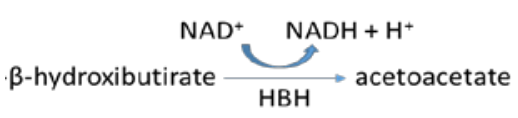

The curve was adjusted to Michaelis-Menten enzyme kinetics description and constant values were estimated from cyclic voltammetric experiments (Fig. 3). The $K_{m}$ values were found to be $(1.52 \pm 0.03)$ $\mathrm{mM}$. The values reported in the literature for a screen-printed iridium-modified working electrode was $\left(2.26 \pm 0.238 \mathrm{mM}\right.$, at $\left.25.8{ }^{\circ} \mathrm{C}\right)$ [13] and with Single-walled carbon nanotubes-modified screen printing electrode (SWCNT-modified SPCE) were $4.61 \mathrm{mM}(\mathrm{pH} 7.5)$ [14] and $0.41 \mathrm{mM}$ at $\mathrm{pH} 8.5$ (0-33 mMNAD) [42]. These data are near and in the same order of magnitude of the present. Although the $\mathrm{K}_{\mathrm{m}}$ parameters can be used to evaluate the enzyme activity, it is possible to see that the $\mathrm{K}_{\mathrm{m}}$ values diminish with the temperature and that at $37.5{ }^{\circ} \mathrm{C}$ its value is $(1.83 \pm 0.302) \mathrm{mM}[13]$.

It is possible to use the linear fit between $1 \mathrm{mM}$ and $3 \mathrm{mM}$ of $\beta$-hydroxybutyrate to identify the ketone quantity present in blood samples, Fig. 3. This detection range is useful to perceive the ketonaemia and can be used for clinical measurements.

These electrodes were also used to examine the formal potential variation with the $\mathrm{pH}$ in the presence of 3- $\beta$-hydroxybutyrate (10 mM) (Fig. 4).

The formal potential in electrolytes is almost constant in all the $\mathrm{pH}$ range (Insertion), but after the addition of 3- $\beta$-hydroxybutyrate it varies (Fig. 4). From the experimental data it was possible to estimate $\mathrm{p} K_{\mathrm{a} 1}=4.0, \mathrm{p} K_{\mathrm{a} 2}=10.2$. These constants can be attributed 


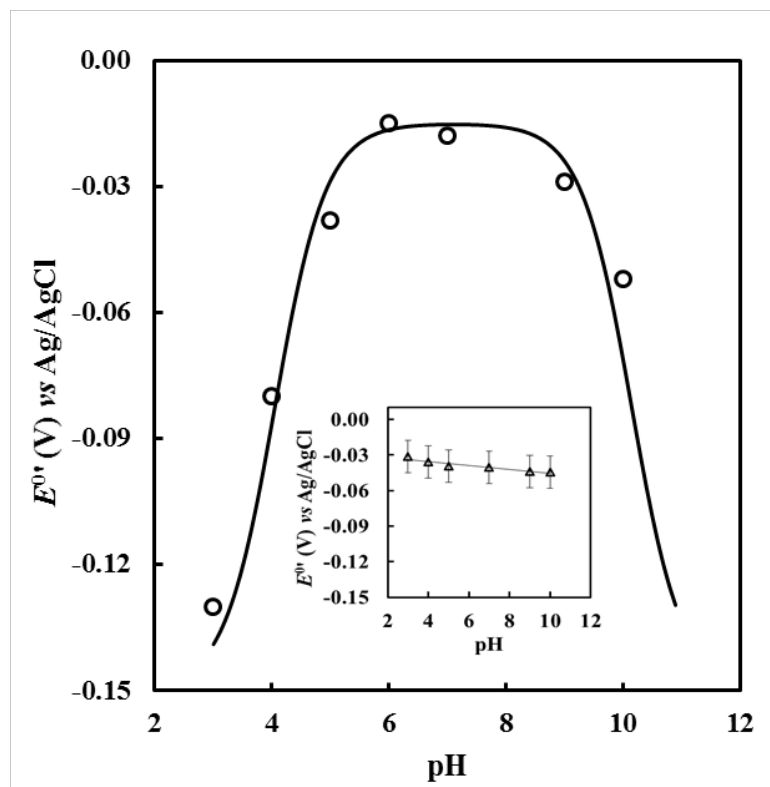

Fig. 4 Variation the formal potential with the $\mathrm{pH}$. The best curve fit allowed the estimation of $\mathrm{p} K_{\mathrm{a} 1}=4.0, \mathrm{p} K_{\mathrm{a} 2}=10.2$. Measurements with different electrodes each point is the media of two measurements with different electrodes. Insertion: formal potential variation with the $\mathrm{pH}$.

to the aspartic acid $\left(\mathrm{p} K_{\mathrm{a}} 3.9\right)$ or glutamic acid $\left(\mathrm{p} K_{\mathrm{a}} 4.0\right)$ and Tyrosine (10.46) respectively [43]. In fact, near the catalytic center there is one residue that has an important paper in the catalysis, Trp155. It is worthwhile to mention that in crystal structure the HB is the molecule that binds to the catalytic center (not acetoacetate), as well as $\mathrm{NAD}^{+}$(not $\mathrm{NADH}$ ). Hydrophilic interactions are established in the complex $\mathrm{HBH}-\mathrm{NAD}^{+}$-HB thought the bounded of $\mathrm{HBH}$ by the two carboxylate oxygen's through four hydrogen bonds. But HB is also accommodated in a hydrophobic pocket surrounded by Ala143, His144 and Trp187 e Trp257 [17]. So these experimental results are in agreement with the crystal data.

\subsection{Influence of Interferentes Species in the Catalysis of $\mathrm{HBH}$}

The main goal of this project was to construct an electrode that could be used to analyze diabetic's blood. So it was necessary to examine the interference of glucose and ascorbic acid usually present in blood. The rapid detection of these three compounds (glucose, ascorbic acid and 3- $\beta$-hydroxybutyrate) in serum and blood may permit a reliable diagnose not only of glycaemia but also of ketonaemia. In order to analyze the specificity of this sensor, the formal potential signal variation with glucose was studied. In amounts between 5-150 $\mathrm{mM}$ the glucose presence did not implicate a change in formal potential, $E^{0,}=(-32 \pm 5)$ $\mathrm{mV}$ vs. $\mathrm{Ag} / \mathrm{AgCl}$. These findings indicate that the redox center where glucose is being detected is also the catalytic center. The catalytic currents $\mathrm{i}_{\mathrm{p}}{ }^{\text {cat }}$, calculated as the rate $i_{\mathrm{p}}{ }^{\mathrm{a}}$ after $/ i_{\mathrm{p}}{ }^{\mathrm{a}}$ before glucose addition, had an increase in low concentration, but to values higher than $25 \mathrm{mM}$ there was a decrease, and after $50 \mathrm{mM}$ the $\mathrm{i}_{\mathrm{p}}{ }^{\text {cat }}$ values do not change with glucose addition (Fig. 5).

Nevertheless, in healthy people the glucose range is from $4.4 \mathrm{mM}$ to $6.6 \mathrm{mM}$ [3]. So, to use this electrode in real samples we must do careful analysis of the results because glucose may compete with HB, increasing artificially the electrochemical signal which may be read as an increase in HB amounts.

The presence of ascorbic acid was also studied. The electrochemical signal variation, before and after the addition of ascorbic acid was analyzed. In quantities in the range of $28 \mu \mathrm{M}$ to $2.8 \mathrm{mM}$ the catalytic current (rate $\mathrm{i}_{\mathrm{p}}{ }^{\mathrm{a}}$ after $/ \mathrm{i}_{\mathrm{p}}{ }^{\mathrm{a}}$ before the addition) was $1.36 \pm 0.09$. However, for concentrations higher than $2.8 \mathrm{mM}$ a

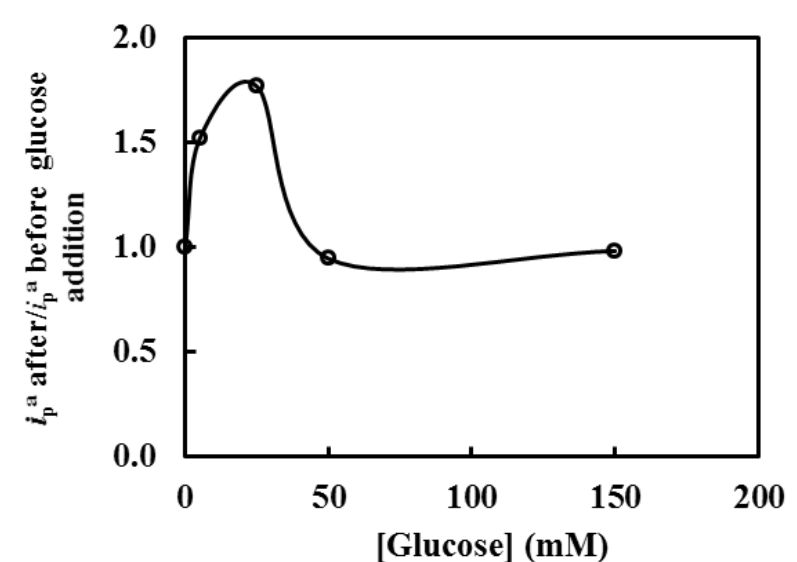

Fig. 5 Variation of $i_{p}{ }^{c a t}\left(i_{p}{ }^{a}\right.$ after $/ i_{p}{ }^{a}$ before glucose addition) with glucose concentration. The cyclic voltammograms were recorded with a scan rate $100 \mathrm{mVs}^{-1}$ in the electrolyte (PBS Buffer (pH 7) with $\mathrm{KCl}(0.1 \mathrm{M})$ ), in the presence of $\mathrm{HB}$ (10 mM). 
greater increase in catalytic current peaks is observed. It is interesting to highlight that the maximum quantity of ascorbic acid in plasma in a recent study was reported to be $100 \mu \mathrm{mol} / \mathrm{L}$ [44], and the reference range in the blood is between $34 \mu \mathrm{mol} / \mathrm{L}$ and $113 \mu \mathrm{mol} / \mathrm{L}$. So with this in mind, and the slight increase observed in the catalytic current for concentrations below $2.8 \mathrm{mM}$, it's necessary to look at the results carefully when a clinical diagnosis is done. It is clear from our data that not only the presence glucose can induce in mistaken diagnoses of hyperketonaemia but also the ascorbic acid.

\section{Conclusions}

In this work we used a simple but efficient procedure to immobilize the enzyme (3-hydroxybutyrate dehydrogenase) and the cofactor (NADH) in the matrix of the working electrode. We use the cofactor NADH to ensure the enzyme activity. This method does not need any drastic treatment, so the enzyme maintains the native conformation without denaturation. This fabrication proceeding also allowed not only the detection and quantifications of the 3 - $\beta$-hydroxybutyrate in the range of interest $1-3 \mathrm{mM}$, but also the catalysis study.

It was possible to verify that the catalytic center was also the redox center in non-turnover conditions, and we also could identify the amino acid responsible for that (Trp). This attribution was based on experimental data that corroborate the crystallographic data's publish recently.

It's important to highlight that this research is driven by the need of a more reliable diagnosis of diabetes, and the development of biodegradable, cheap but reliable 3- $\beta$-hydroxybutyrate biosensors. In future research, this biosensor should be tested with human blood, to evaluate its efficacy, reliability and usefulness in in vivo situations.

\section{References}

[1] Wild, S., Roglic, G., Green, A., Sicree, R., and King, H. 2004. "Global Prevalence of Diabetes: Estimates for the
Year 2000 and Projections for 2030.” Diabetes Care 27 (5): 1047-53.

[2] Shaw, J., Sicree, R., and Zimmet, P. 2010. "Global Estimates of the Prevalence of Diabetes for 2010 and 2030.” Diabetes Res. Clin. Pract. 87 (1): 4-14.

[3] Wang, J. 2008. "Electrochemical Glucose Biosensors." Chem. Rev. 108: 814-25.

[4] Pitkin, A., and Rice, M. J. 2009. "Challenges to Glycemic Measurement in the Perioperative and Critically III Patient: A Review.” Diabetes Sci. Technol. 3: 1270-81.

[5] Tonyushkina, K., and Nichols, J. 2009. "Glucose Meters: A Review of Technical Challenges to Obtaining Accurate Results.” J. Diabetes Sci. Technol. 3 (4): 971-80. doi: 10.1177/193229680900300446.

[6] Boren, S., and Clarke, W. 2010. "Analytical and Clinical Performance of Blood Glucose Monitors.” J. Diabetes Sci. Technol. 4: 84-97.

[7] Yoo, E-H., and Lee, S-Y. 2010. "Glucose Biosensors: An Overview of Use in Clinical Practice.” Sensors 10: 4558-76. doi:10.3390/s100504558.

[8] Chin, C., Linder, V., and Sia, S. 2012. "Commercialization of Microfluidic Point-of-Care Diagnostic Devices.” Lab on a Chip. 12: 2118-34. Doi: 10.1039/c2Ic21204h.

[9] Sacks, D., Arnold, M., Bakris, G., Bruns, D., Horvath, A., Kirkman, S., Lernmark, A., Metzger, B., and Nathan, D. 2011. "Position Statement Executive Summary: Guidelines and Recommendations for Laboratory Analysis in the Diagnosis and Management of Diabetes Mellitus.” Diabetes Care 34 (6): 1419-23. doi: 10.2337/dc11-9997.

[10] Kwan, R., Hon, P., Mak, W., Hu, L., and Renneberg, J. 2006. "Biosensor for Rapid Determination of 3-Hydroxybutyrate Using Bienzyme System.” Biosensors \& Bioelectronics 21: 1101-6. DOI 10.1016/j.bios.2005.04.005.

[11] Laffel, L. 1999. "Ketone Bodies: A Review of Physiology, Pathophysiology and Application of Monitoring to Diabetes.” Diabetes Metab. Res. Rev. 15 (6): 412-26.

[12] Fang, L., Wang, S. H., and Liu, C. C. 2008. "An Electrochemical Biosensor of the Ketone 3-[Beta]-Hydroxybutyrate for Potential Diabetic Patient Management." Sensors and actuators B 129: 818-25.

[13] Khorsand, F., Riahi, S., Fard, S., Kashanian, S., Naeemy, A., Larijani, B., and Omidfar, K. 2013. "Development of 3-Hydroxybutyrate Dehydrogenase Enzyme Biosensor Based on Carbon Nanotube-Modified Screen-Printed Electrode.” Nanobiotechnology 7 (1): 1-6.

[14] Forrow, N., Sanghera, G., Walters, S., and Watkin, J. 2005. "Development of a Commercial Amperometric Biosensor Electrode for the Ketone D-3-Hydroxybutyrate.” Biosens. Bioelectron 20 (8): 1617-25. 
[15] Li, G., Ma, N., and Wang, Y. 2005. "A New Handheld Biosensor for Monitoring Blood Ketones.” Sensors and Actuators B: Chemical 109: 285-90.

[16] Kanazawa, H., Hoque, M. M., Tsunoda, M., Suzuki, K., Yamamoto, T., Kawai, G., Kondo, J., and Takenaka, A. 2016. "Structural Insights into the Catalytic Reaction Trigger and Inhibition of D-3-Hydroxybutyrate Dehydrogenase.” Acta. Crystallogr. Sect. F 72: 507-15.

[17] Wooten, M., and Gorski, W. 2010. "Facilitation of NADH Electro-Oxidation at Treated Carbon Nanotubes.” Anal. Chem. 82: 1299-304. Doi: 10.1021/ac902301b.

[18] Govindhan, M., Amiri, M., and Chen, A. 2015. “Au Nanoparticle/Graphene Nanocomposite as a Platform for the Sensitive Detection of NADH in Human Urine.” Biosensors and Bioelectronics 66: 474-80.

[19] Ali, I., and Omanovic, S. 2013. "Kinetics of Electrochemical Reduction of $\mathrm{NAD}^{+}$on a Glassy Carbon Electrode.” Int. J. Electrochem. Sci. 8: 4283-304.

[20] Florou, A., Prodromidis, M., Karayannis, M., and Tzouwara-Karayann, T. 1998. "Electrocatalytic Oxidation of NADH in Flow Analysis by Graphite Electrode Modified with 2,6-Dichlorophenolindophenol Salts.” Electroanalysis, 10: 1261-8.

[21] Arvite, A., Valentini, F., Radoi, A., Arduini, F., Tamburri, E., Rotariu, L., Palleschi, G., and Bala, C. 2007. “The NADH Electrochemical Detection Performed at Carbon Nanofibers Modified Glassy Carbon Electrode.” Electroanalysis 19: 1455-9.

[22] Zanardi, C., Ferrari, E., Pigani, F., and Seeber, R. 2015. "Development of an Electrochemical Sensor for NADH Determination Based on a Caffeic Acid Redox Mediator Supported on Carbon Black.” Chemosensors 3: 118-28.

[23] Sahin, M., and Ayranci, E. 2015. "Electrooxidation of NADH on Modified Screen-Printed Electrodes: Effects of Conducting Polymer and Nanomaterials.” Electrochimica Acta. 166: 261-70.

[24] Álvarez-González, I., Saidman, S., Lobo-Castañón, Miranda-Ordieres, A., and Tuñón-Blanco, P. 2000. "Electrocatalytic Detection of NADH and Glycerol by $\mathrm{NAD}^{+}$-Modified Carbon Electrodes.” Anal. Chem. 72: 520-7.

[25] Blanco, E., Foster, C., Cumba, L., Carmo, D., and Banks, C. 2016. "Can Solvent Induced Surface Modifications Applied to Screen-Printed Platforms Enhance Their Electroanalytical Performance?” Analyst 141: 2783-90.

[26] Shimomura, T., Sumiya, T., Ono, M., Ito, T., and Hanaoka, T. 2013. “A Novel, Disposable, Screen-Printed Amperometric Biosensor for Ketone 3-B-Hydroxybutyrate Fabricated Using a 3- $\beta$-Hydroxybutyrate Dehydrogenase-Mesoporous Silica Conjugate.” Analytical and Bioanalytical Chemistry 405: 297-305.
[27] Kumar, A., and Chen, S-M. 2008. "Electroanalysis of NADH Using Conducting and Redox Active Polymer/Carbon Nanotubes Modified Electrodes-A Review.” Sensors 8: 739-66.

[28] Roland, C. 2014. "Paper-Based Analytical Devices for Point-of-Care Infectious Disease Testing.” Eur J. Clin. Microbiol Infect Dis. 33: 147-56. DOI:10.1007/s10096-013-1945-2.

[29] Manso, J., Mena, M., Yáñez-Sedeño, and Pingarrón, J. 2008. "Alcohol Dehydrogenase Amperometric Biosensor Based on a Colloidal Gold-Carbon Nanotubes Composite Electrode.” Electrochimica Acta. 53: 4007-12.

[30] Punckt, C., Pope, M., Liu, J., Lin, Y., and Aksay, I. 2010. "Electrochemical Performance of Graphene as Affected by Electrode Porosity and Graphene Functionalization.” Electroanalysis 23: 2834-41.

[31] Kochius, S., Magnusson, A., Hollmann, F., Schrader, J. and Holtmann, D. 2012. "Immobilized Redox Mediators for Electrochemical NAD(P) ${ }^{+}$Regeneration.” Appl. Microbiol Biotechnol 93: 2251-64.

[32] Popescu, I., Domínguez, E., Narváez, A., Pavlov, V., and Katakis, I. 1999. "Electrocatalytic Oxidation of NADH at Graphite Electrodes Modified with Osmium Phenanthrolinedione." Journal of Electroanalytical Chemistry 464: 208-14.

[33] Tan, B., Hickey, D., Milton, R., Giroud, F., and Minteer, S. 2015. "Regeneration of the NADH Cofactor by a Rhodium Complex Immobilized on Multi-walled Carbon Nanotubes.” Journal of the Electrochemical Society 162: H102-7. DOI: 10.1149/2.0111503jes.

[34] Radoi, A., Compagnone, D., Valcarcel, M., Placidi, P., Materazzi, S., Moscone, D., and Palleschi, G. 2008. "Detection of NADH via Electrocatalytic Oxidation at Single-Walled Carbon Nanotubes Modified with Variamine Blue.” Electrochimica Acta. 53: 2161-9.

[35] Taleat, Z., Khoshroo, A., and Mazloum-Ardakani, M. 2014. "Screen-Printed Electrodes for Biosensing: A Review (2008-2013).” Microchim Acta. 181: 865-91. Doi: 10.1007/s00604-014-1181-1.

[36] Mohamed, H. 2016. "Screen-Printed Disposable Electrodes: Pharmaceutical Applications and Recent Developments.” Trends in Analytical Chemistry 82: 1-11.

[37] Skeika, T., Zuconelli, C., Fujiwara, S., and Pessoa, C. 2011. "Preparation and Electrochemical Characterization of a Carbon Ceramic Electrode Modified with Ferrocenecarboxylic Acid.” Sensors 11: 1361-74. Doi. 10.3390/S110201361.

[38] Sekretaryova, A., Eriksson, M., and Turner, A. 2016. "Bioelectrocatalytic Systems for Health Applications." Biotechnology Advances 34:177-97.

[39] Freire, R., Pessoa, C., Mello, L., and Kubota, L. 2003. 
"Direct Electron Transfer: An Approach for Electrochemical Biosensors with Higher Selectivity and Sensitivity.” J. Braz. Chem. Soc. 14 (2): 230-43.

[40] Léger, C., and Bertrand, P. 2008. "Direct Electrochemistry of Redox Enzymes as a Tool for Mechanistic Studies.” Chem. Rev. 108: 2379-438. doi: 10.1021/cr0680742.

[41] Bard, A., and Faulkner, L. 2001. In Electrochemical Methods, Fundamentals and Applications. 2ed, New York: Wiley.

[42] Nicholson, R. 1965. "Theory and Application of Cyclic Voltammetry for Measurement of Electrode Reaction Kinetics.” Analitical Chemistry 11: 1351-5.
[43] Bergmeyer, H., Gawehn, K., Klotzsch, H., Krebs, H., and Williamson, D. 1967. "Purification and Properties of Crystalline 3-Hydroxybutyrate Dehydrogenase from Rhodopseudomonas Spheroides." Biochem. J. 102: 423-31.

[44] Voet, D., and Voet, J. 2004. Biochemistry. 3th edition, John Wiley \& Sons, inc. (USA).

[45] Levine, M., Padayatty, S. J., and Espey, M. G. 2011. Vitamin C: A Concentration-Function Approach Yields Pharmacology and Therapeutic Discoveries.” Advances in Nutritio. 2: 78-88. http://dx.doi.org/10.3945/an.110.000109. 